\title{
Design features of agricultural transporting technological device equipped with agrophilic wheel mower
}

\author{
Sergey Popov ${ }^{1}$, Dmitry Komissarov ${ }^{1}$, Alexander Lavrov,, ${ }^{2}$ Anatoly Gulyaev², and Valery \\ Davydov $^{3}$ \\ ${ }^{1}$ Center of technical cooperation at MGTU named N.E. Baumana, Gospitalniy pereulok, 10, Moscow, \\ 105005, Russia \\ ${ }^{2}$ Federal Scientific Agro-Engineering Center VIM, 1 Institutsky proezd, 5, Moscow, 109428, Russia \\ ${ }^{3}$ Belarusian National Technical University, Independence Ave., 65, 1st building, Minsk, 220013, \\ Belarus
}

\begin{abstract}
Now days there is no a single mass-produced vehicle for agriculture which does not match requirements of the state standard for the maximum allowable impact of movers on the soil. This leads to significant losses and under-harvest of agricultural products. As a promising direction for increasing the efficiency of the transport infrastructure of agricultural production, it is proposed to develop an environmentally friendly transport and technological chassis for agricultural purposes.
\end{abstract}

\section{Introduction}

Russian agriculture suffers heavy losses due to the lack of equipment for working on soils with low bearing capacity in wet and morewet conditions. This leads to the fact that winter harvesting lasts more than 40 days, the loss is $42 \%$. In rainy years, It is need to increases the number of harvesting and transport equipment, but this equipment cannot go into the field and is inactive. In such way It is necessary to develop technological devices for carrying out transporting and technological processes in adverse weather conditions to increase the efficiency of agriculture. A number of crops, such as soybeans and rice, are grown using water checks, which makes special difficult to export crops from combine harvesters. About $40 \%$ of the soil surface is compacted by wheels of technological devices in the process of fertilizing. Soil compaction contributes to the formation of large and dense blocks during plowing, which worsen the conditions for normal plant growth.

Existing transport and technological devices (TTD) don't fully match the agriculture requirements for a further increase in labor productivity, eliminating the harmful effects of movers on the soil, reducing losses and shortage of crops and reducing fuel consumption during cargo transportation [1,2,3].

This significantly reduces the efficiency of transport and technological means during the

\footnotetext{
* Corresponding author: vimlavrov@mail.ru
} 
production process, and as a result, the productivity of agricultural production.

The solution of the problem is to develop a domestic transport and technological device (TTD) equipped with «agrophilic» wheel mower.

Reducing the maximum pressure from the wheels to the land cover is possible either by increasing the number of wheels or by increasing the size of the tires. Excessive increase in the number of wheels is impractical, as it leads to a significant complication and increase in the mass of the transmission and to the need to manufacture original units. The increase in tire size allows the use of the aggregate base of production cars, but requires the use of an unconventional layout scheme that compensates for the reduction in chassis maneuverability. At the same time, the design of the TTC is significantly affected by the need to comply with the existing dimensional restrictions, first of all, restrictions on the width of the machine.

The implementation of a comprehensive solution combining the use of increased dimension tires in the design of a TTS with the original chassis design and with the maximum use of components and assemblies of multi-purpose trucks ensures a reduction in the cost and costs of their production and operation. At the same time, the adaptation of the chassis, transmission and steering units of serial machines to the conditions of a new application is necessarily carried out.

The basic agrotechnical requirements for the agricultural technical TTD were developed at the Federal State Budget Scientific Institution of Science and Technology of the VIM. These requirements are based on the existing scientific and technical reserve, the results of the analysis of promising agricultural technologies and existing requirements to limit the impact on the soil [4-7]. The layout and design study of the TTD on increased tires, including but not limited to adapting the transmission and steering of mass-produced cars to agrotechnical requirements, was carried out at the Technical Cooperation Center at MSTU named N.E. Bauman group of designers with experience in similar developments [8-10].

A general view of the TTD agricultural purpose is shown in figure 1.
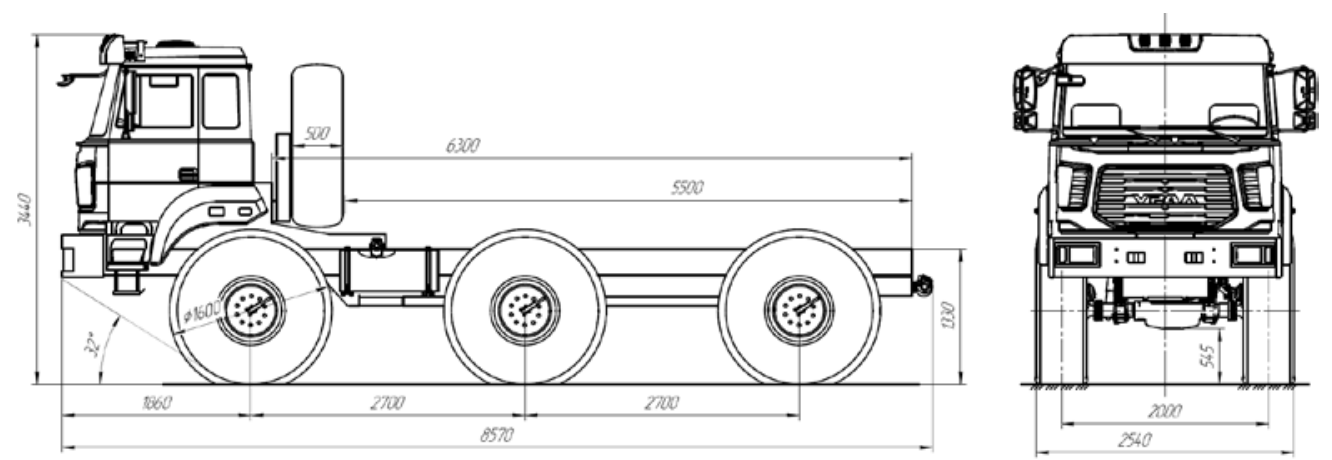

Fig. 1. General view of agricultural technical TTD

\section{Materials and methods}

«Agrophilic» Wheel Movers. Wheel movers of modern trucks provide the opportunity to reduce ground pressure due to the design features of highly elastic tires and the use of a tire pressure regulation system. For multi-purpose vehicles, the driving mode with reduced air pressure in the tires is used to overcome off-road areas, but its use leads to a decrease in tire life. In agricultural conditions, special «agrophilic» mowers with tires allowing long-term operation at reduced pressure should be used. Table 1 summarizes the main technical 
requirements for tires of «agrophilic» TTD mower systems for agricultural purposes.

Table 1. Main requirements for tires of «agrophilic» TTD mowers systems for agricultural purposes

\begin{tabular}{|l|l|}
\hline Parameter & Value \\
\hline The most permissible load, not less, $\mathrm{kN}$ & 35 \\
\hline Maximum pressure on the soil with reduced tire pressure, $\mathrm{kN}$, not more & 60 \\
\hline $\begin{array}{l}\text { The value of the permissible level of lowering the air pressure, bar, no } \\
\text { more }\end{array}$ & $0,3 \ldots 0,5$ \\
\hline Allowed speed on improved roads, at least, $\mathrm{km} / \mathrm{h}$ & 70 \\
\hline Type & Diagonal \\
\hline Tire diameter mm & 1600 \\
\hline Profile Width mm & 500 \\
\hline
\end{tabular}

Constructive Adapted Transmission. Constructively adapted transmission (CAT) provides torque transmission from the engine in the entire range of rotational speeds and its optimized distribution along the wheels of the TTD

The CAT construction provides a change in the torque and frequency of rotation of the wheels of the TTD in the required range, taking into account the requirements for both transport vehicles (cars) and technological units for agriculture. Adapted CAT units and assemblies provide maximum unification with commercially available units for parts and assemblies.

CAT and TTD shown in figure. 1 includes:

- a gearbox from the range of commercially available products;

- transfer case adapted to the new layout scheme;

- front and rear axles;

- middle axle with adapted final drive and with center differential;

- cardan transmission.

Schematic diagram of a CAT with an engine and clutch is shown on the Fig. 2, and table 2 - its technical characteristics.

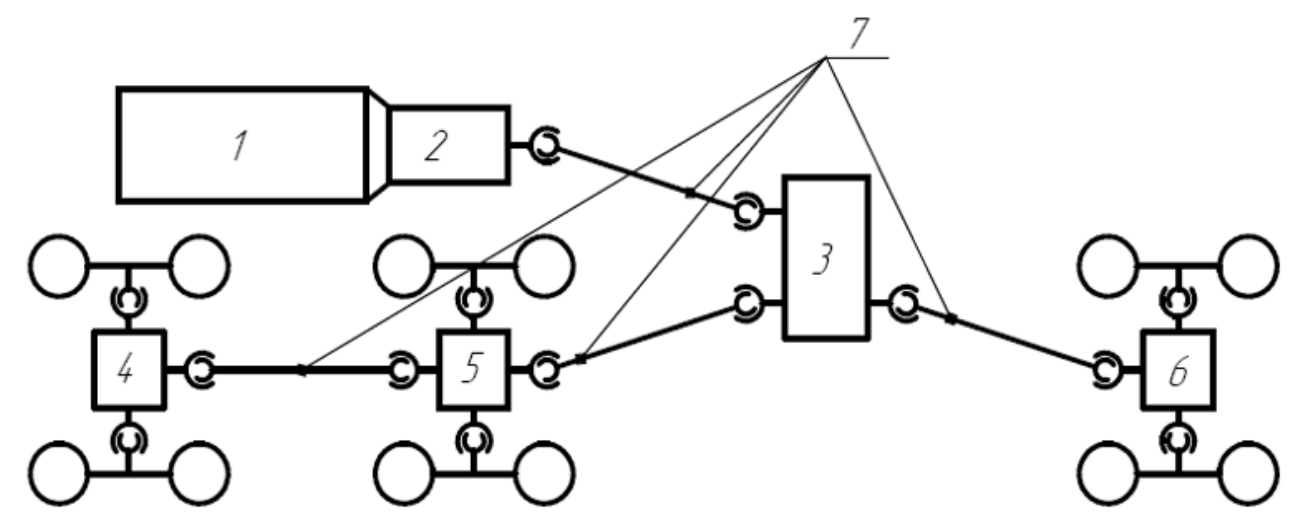

Fig. 2. Schematic diagram of CAT: 1 - engine with clutch; 2 - gearbox; 3 - transfer case (TC) with a center differential lock; 4 - front axle; 5 - middle bridge with a center differential lock; 6 - rear axle; 7 - driveshaft. 
Table 2. Main technical characteristics of CAT

\begin{tabular}{|l|c|}
\hline Parameter & Value \\
\hline Maximum input torque, $\mathrm{N}$ * $\mathrm{m}$ & 1130 \\
\hline Maximum input rotation frequency, rpm & 2300 \\
\hline Minimal input rotation frequency, rpm & 800 \\
\hline Nominal rated torque, $\mathrm{N}$ * $\mathrm{m}$, on the input shaft of the TC & 6570 \\
\hline Maximum allowable torque, $\mathrm{N}$ * $\mathrm{m}$, on the input shaft of the TC & 8830 \\
\hline
\end{tabular}

Adapted steering system. Adaptive steering system (ASS) provides control of the direction of movement of the TTD in three modes.

1) Transport. When the steering wheel is rotated, the steering system (SS) with the help of a hydraulic amplifier through levers and rods rotates the steered wheels of the first and second axles.

2) Technological turn. When the steering wheel is rotated, the SS rotates the steered wheels of the first and second axles. In this case, a thruster unit (TU) rotates the wheels of the second and third axles in the opposite direction.

3) Technological bias. When the steering wheel is rotated, the RU rotates the steered wheels of the first and second axles. In this case, a thruster unit (TU) rotates the wheels of the second and third axles in the same direction.

In Fig. 3 presents a schematic diagram of the control of the ASS.

The transport mode of movement is carried out in the entire range of speeds of the TTD.

Technological control mode is carried out at a speed of TTD not exceeding 25 ... $30 \mathrm{~km}$ / h.
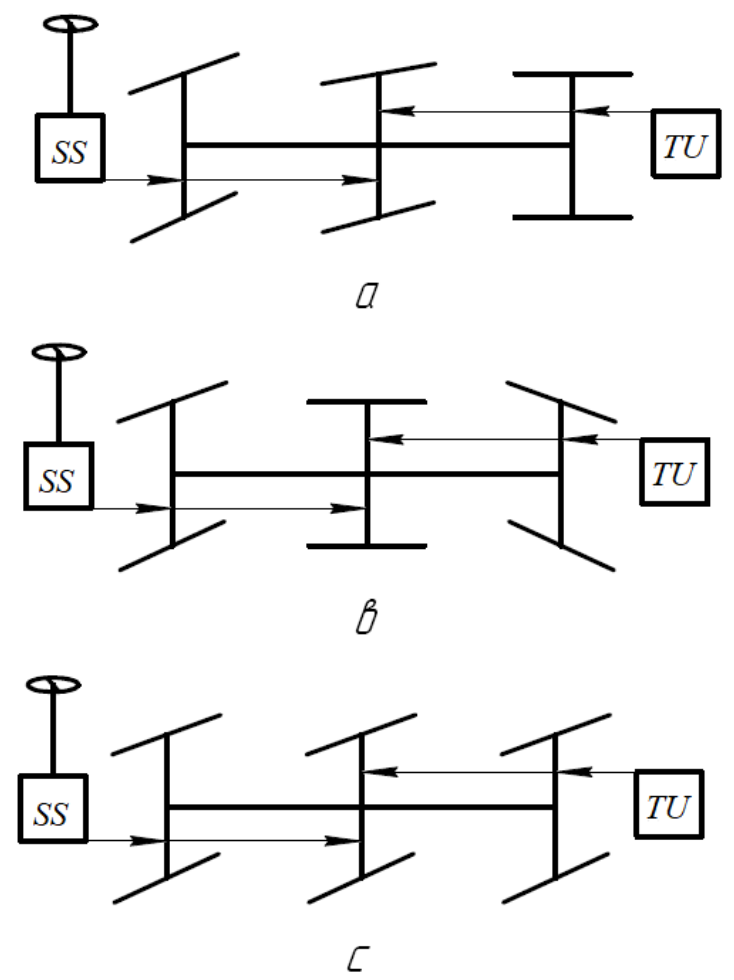

Fig. 3. Schematic diagram of the control of the ASS: a — transport mode; в — Technological turn mode ; c — Technological bias mode; SS — the steering system; TU — the thruster unit. 
Intial vehicle. The initial vehicle used to adapt to the conditions of agricultural production is a serial truck URAL-4320-80 / 82 from URAL AP.

The Ural-4320 car is a multi-purpose off-road truck designed for the transport of goods, passengers and equipment in various fields of activity, including in agriculture and forestry. It is distinguished by simplicity of design, high reliability, maintainability, low cost popularity.

The main technical characteristics of URAL-4320-80 / 82 (URAL AP, Russia) are presented in table 3 .

Table 3. Main characteristics of URAL - 4320-80 / 82 (URAL AP, Russia)

\begin{tabular}{|l|l|}
\hline Parameter & Value \\
\hline Wheel formula & $6 \times 6$ \\
\hline Main overall dimensions of the chassis & $7890 \times 2500 x 3375$ \\
\hline Mounting frame length, mm & 5200 \\
\hline Operational weight, kg & 8685 \\
\hline The mass of the transported freight, kg & 8500 \\
\hline $\begin{array}{l}\text { Permissible trailer mass on roads of 1-4 categories / 5 categories and } \\
\text { terrain, kg }\end{array}$ & $11500 / 7000$ \\
\hline Engine operating power, kW & $175-202$ \\
\hline Maximum speed, km / h & 90 \\
\hline Minimum speed, km / h & 3 \\
\hline Agrotechnical clearance, mm & 400 \\
\hline Turn radius, m & 13 \\
\hline Tires & $425 / 85 R 21$ \\
\hline
\end{tabular}

To determine the theoretical method of the maximum contact pressure of the TTS wheel propulsors on the soil, an assessment technique was applied using the universal characteristics of the tire [11].

\section{Results and discussion}

TTD with an adaptive steering system and transmission, developed designed using components and assemblies of the automotive industry, including from the range used by Automobile Plant URAL (AP URAL).

Estimated functional purposes of this TTD:

- transportation of crops of grain, root crops and other crop products;

- transportation of liquid mineral fertilizers in tanks;

- spreading solid and mineral fertilizers;

- use as a mobile workshop;

- transportation of fuels and lubricants in tanks;

- transportation of water, milk, aquaculture;

- use as a dump truck for transportation of bulk cargo;

- use as a technological tower, drilling rig;

- transportation of people in off-road conditions;

- other traction and technological operations.

The main technical characteristics of the TTD equipped with «agrophilic» wheel mower are presented in table 4.

Comparative analysis of the data table. 4 showed that measures to adapt the design of a Ural-4320 truck to agricultural conditions have improved its basic technological qualities: reduce the maximum pressure on the soil from 200 to $65 \mathrm{MPa}$; increase agrotechnical clearance from 400 to $545 \mathrm{~mm}$; reduce the turning radius from 13 to $11.2 \mathrm{~m}$, as well as provide new technological properties (control of TTD displacement). Thus, the developed 
TTS and fully complies with modern agrotechnical requirements.

Table 4. The main technical characteristics of the TTD equipped with «agrophilic» wheel mower and a serial car URAL - 4320-80 / 82 (with a comparative assessment of technological qualities)

\begin{tabular}{|l|l|l|c|}
\hline Parameter & TTD & URAL & $\begin{array}{l}\text { Change in technological } \\
\text { properties, }+/-\end{array}$ \\
\hline Mounting frame length, mm & 5500 & 5200 & +300 \\
\hline Operational weight, kg & 9600 & 8685 & +915 \\
\hline Maximum load capacity, kg & 6000 & 8500 & -2500 \\
\hline Engine operating power & 300 & 300 & 0 \\
\hline Maximum velocity & 70 & 90 & -20 \\
\hline Minimum velocity & 3,6 & 4 & $-0,6$ \\
\hline Agrotechnical clearance & 545 & 400 & 145 \\
\hline Pressure on the soil (estimated), KPa & 65 & 200 & +135 \\
\hline Turn radius, m & 11,2 & 13 & $-1,8$ \\
\hline Technological shift & Yes & No & + \\
\hline
\end{tabular}

Comparative analysis of the data (table. 4) showed that operations for adaption construction of the Ural-4320 truck to agricultural conditions have improved its main technological qualities: reduce the maximum pressure on the soil from 200 to $65 \mathrm{MPa}$; increase agrotechnical clearance from 400 to $545 \mathrm{~mm}$; reduce the turning radius from 13 to $11.2 \mathrm{~m}$, as well as provide new technological properties (control of TTC displacement). Thus, the developed TTS fully complies with modern agrotechnical requirements.

\section{Conclusions}

VIM's research showed that the use of «agrofilic» wheel mowers on the URAL vehicle will make this vehicle acceptable for use in various technological operations of agricultural production. At the same time, these engines will increase the environmental safety of the car and ensure its high traffic, especially during the early spring and late autumn when working on weakly bearing soils.

At the same time, fuel consumption is reduced by 1.22 times (saving up to $4000 \mathrm{~kg}$ of fuel per year on only one machine). Preliminary researches have shown that the use of environmentally friendly wheel propellers on agricultural transport and technology means reduces soil pressure by 3-4.5 times, increases the traction and coupling properties of the machine by 1.5-2 times, and labor productivity by $1.1-1.4$ times.

\section{References}

1. Godzhaev Z.A., Izmailov A.Yu., Evtyushenkov N.E., Kryukov M.L. On the issue of creating environmentally friendly all-season agricultural vehicles. // Tractors and agricultural machinery. - 2016. - No. 3. - p. 48-52.

2. Popov S.D. Problems and prospects of creating a mobile transport and technological complex for agricultural purposes Izvestia International Academy of Agricultural Education. Issue No. 36 (2017). p 106 - 113. November 2017

3. Izmailov A.Yu., Evtyushenkov N.E. Forecast of transport support for agricultural production. // Agricultural machinery and technology. - 2010. - No. 1. - p. 16-20.

4. Izmailov, A., Shevtsov, V., Lavrov, A., Godzhaev, Z. et al., "Application of the universal tire characteristic for estimating the maximum pressure of a pneumatic tractor wheel on the ground," SAE Technical Paper 2015-01-2760, 2015, doi: 10.4271 / 2015-01-2760.

5. Shevtsov, V.G., Soloveychik, A.A., Rusanov, A.V., \& Lavrov, A.V. (2014). The use of universal characteristics of a tire in determining maximum pressure of a wheel running 
on soil. Proceedings of the International Research \& Practice Video Conference: Topical research trends in the twenty-first century: Theory and practice (p. 169-173). Voronezh, Russia: Voronezh Public Forest Engineering Academy.

6. Rusanov, V.A. The problem of soil compaction movers and effective ways to solve it. Moscow, Russia: all-Russian Institute of mechanization.

7. Lavrov, A.V., Kryukovskaya, N.S., \& Petrischev, N.A. Evaluation of impact on soil wheel drivers of self-propelled selection seeder. Agrimachinery and Energy, 4 (21), p.95-106.

8. Popov S.D. Fundamental problems of the development of internal transport in sparsely populated regions of Russia and ways to solve it based on the development of highly mobile road transport complexes (on the example of the Arkhangelsk region). Economics, project management, education, law, ecology, medicine, sociology, philosophy, philology, psychology, technology, mathematics: state and development prospects. Sat articles on the basis of the International scientific-practical conference. July 04-05, 2013, St. Petersburg, KultInformPress, 2013, -148 p. ISBN 978-5-83920411-9, p. 110-117. 2013

9. Sarkisov P., Popov S. Active tire pressure control as a step to sustainable automotive mobility. Proceedings of Multidisciplinary Academic Conference on Transport, Logistics and Information Technologies (MAC - TLIT 2013). 1st ed., Prague. MAC Prague consulting Ltd. 2013

10. Boris N. Belousov,. Popov. Heavy-Duty Wheeled Vehicles: Design, Theory, Calculations Published by SAE International with a Product Code of R-419, ISBN of 978-0-7680-7723-0, and 800 pages in a hardbound binding. 2013-12-23, p.800

11. Shevtsov V.G., Soloveichik A.A., Rusanov A.V., Lavrov A.V. Using the universal characteristics of the tire to determine the maximum pressure of the wheel propulsion on the soil Actual directions of scientific research of the XXI century: theory and practice. 2014.V.2. No. 2-2 (7-2). p. 169-173. 